Manuelle Medizin $2021 \cdot 59: 26-32$ https://doi.org/10.1007/s00337-020-00674-6 Published online: 2 April 2020

(C) The Author(s) 2020

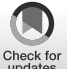

Laura Maltry' - Daniela Ohlendorf' · Michael Bendels ${ }^{1}$ David A. Groneberg' Christoph Mickel ${ }^{2}$

'Institut für Arbeitsmedizin, Sozialmedizin und Umweltmedizin, Goethe-Universität, Frankfurt am Main, Germany

${ }^{2}$ Athlyzer GmbH, Frankfurt, Germany

\title{
Does sleep contribute to the consolidation of motor memory?
}

\section{A literature review}

\section{Introduction}

The debate on if or rather how sleep promotes the process of motor memory consolidation is still in full swing [24]. Although the notion in the literature is that sleep enhances the consolidation of motor memory, sleep deprivation does not necessarily lead to a performance decay $[7,8]$. It is assumed that the new encoding is consolidated during sleep in such a way that the quality of execution is subsequently improved or more stable. During sleep no new encodings disturb the (re-)processing of the latest encodings by occupying the relevant neural networks [44, 49]. It has also been discussed that sleep merely passively protects the traces of memory from decay. For at least a decade it has been suggested that sleep promotes consolidation; however, articles refuting the beneficial contribution have constantly appeared [5, 33]. These contradictory findings have sometimes been attributed to the fact that consolidation, motor learning, memory and also sleep are generic terms for various (neurological) processes, which to date have only been vaguely understood. Therefore, at present the answer to the question whether sleep promotes the consolidation of motor memory can only be answered for differentiated paradigms.

First, the term memory must be defined more precisely for neurophysiological consolidation studies. Classically, motor memory is assigned to non-declarative memory. On the basis of the investigations on a patient H.M. it was long considered that in this area no factual knowledge and consequently no involvement of the hippocampus was necessary [42]. Recently, however, critical considerations of these results appeared and some authors [14, 43] argued that without motorically relevant knowledge, no motor memory can be formed. In the meantime, imaging methods have proven that the hippocampus is of greater importance for the long-term storage of longer movement sequences. This applies to both implicit and explicit tasks [39]. The same applies to the selection of motor tasks for investigations. In order to take the different characteristics of motor tasks into account, they have been further divided into motor (skill) adaptation (MA) and motor skill learning (MSL). A distinction can further be made between implicit and explicit types of tasks [15]. In MA studies a known movement is disturbed by perturbations. Here, a cursor is usually used which is operated by hand and the subject learns to reduce the systematic error. The maximum learning goal is to execute the movement as if there was no disturbance [4]. For MSL research is via serial reaction tasks, usually using fingertip sequences. These must be completed as quickly and as error-free as possible and there is no maximum learning objective here [48]. There is no agreement on the neurophysiological basis of both types of tasks [20]. With respect to consolidation, the involvement of the cerebellum in MA and the striatum in MSL are discussed in particular [15]. Furthermore, offline improvements (OLI) and offline stabilization (OLS) are summarized under the term consolidation: The new memory track is still unstable after the exercise and can be disturbed by interference so that it is not stored for any length of time. The information becomes more stable (OLS) only after an offline phase. Furthermore, it was observed that the exercise quality in the re-test can be better than during the exercise (OLI). Here the memory track seems to be influenced during the offline phase in such a way that it can be recalled without additional practice [25]. Although this concept is based on studies on declarative memory it is now accepted for motor memory as well [4]. Both processes do not run independently but are tested differently [38]. Some groups focused on OLS [26, 40], others looked exclusively at OLI [21, 23].

\begin{tabular}{|ll}
\hline Abbreviations \\
\hline AMPA & $\begin{array}{l}\text { a-Amino-3-hydroxy-5-methyl-4- } \\
\text { isoxazolepropionic acid }\end{array}$ \\
\hline BDNF & Brain-derived neurotrophic factor \\
\hline$E E G$ & Electroencephalography \\
\hline LTP & Long-term potentiation \\
\hline MA & Motor adaptation \\
\hline MSL & Motor skill learning \\
\hline NMDA & N-methyl-D-aspartate \\
\hline NREM & Non-rapid eye movement sleep \\
\hline OLI & Offline improvements \\
\hline$O L S$ & Offline stabilization \\
\hline$P E T$ & Positron emission tomography \\
\hline$R E M$ & Rapid eye movement sleep \\
\hline$S W S$ & Slow wave sleep \\
\hline
\end{tabular}


At the neurophysiological level synaptic and systemic consolidation are also described. Synaptic consolidation takes place in the structures that store what has been learned during the exercise and is based on the processes of long-term potentiation (LTP) [17]. Triggered by extracellular stimuli, such as the practice of a new skill, intracellular processes are triggered that ultimately change the plasticity and effectiveness of synapses [35]. With slower systemic consolidation, the newly encoded memories are moved to other parts of the brain. Here, synaptic consolidation functions as a storage mechanism in the different areas [11]. Although it can be read that this only applies to declarative memory, it has been shown that systemic changes are possible in motor learning as well [16].

The time required for offline phases varies greatly for both OLS and OLI but is usually $4-6 \mathrm{~h}[25,38]$. Another study on super-fast consolidation showed that 3 min can be enough [34]. Sleep also functions as a generic term for various neuronal processes. In the literature on sleep-dependent consolidation, the significance and neurophysiological processes of various electroencephalography (EEG) patterns were investigated. Recent studies increasingly focused on non-rapid eye movement sleep (NREM) $[22,35,51]$. Slow wave sleep (SWS) is thought to promote particularly declarative memory, while the second stage of NREM and rapid eye movement sleep (REM) are more important for procedural memory [41]. Taking a closer look at the current literature, this classification is by no means final. According to the current state of research it is assumed that learning increases with longer periods of sleep; however, effects can also be observed after short sleep phases of 1-2 h and even after very short naps of $6 \mathrm{~min}$ [13]. Imaging techniques were used to gain insights into the activity of the striatum and cerebellum during sleep. Thus, the cerebellum is very active during SWS. In addition, the thalamus, from which the sleep spindles and in part also the delta waves originate, draws afferences from the cerebellum [1]. In REM, the cerebellum is considered responsible for strong atonia and eye movements [12].
In the following an overview over the current literature is given, which aims to present in particular what is known about the contribution of sleep to these characteristics of the consolidation of motor memory. Based on this, the goal is to make recommendations for future studies and, if possible, finally for motor learning in practical use.

\section{Methods}

For this overview a literature search was performed using the metadatabase PubMed. Initially, a snowballing sampling was executed using the keywords consolidation, motor memory, sleep and motor learning, which are described more precisely in the introduction. For the search the terms were combined as follows: consolidation AND sleep, consolidation AND memory, consolidation AND motor learning, sleep AND memory, sleep AND motor learning, memory AND motor learning. The literature screening was carried out by one independent investigator. Subsequently, for each generic term, keywords describing a distinct part were included in the search. For consolidation, the terms synaptic consolidation and systemic consolidation were added. Memory was changed to motor memory for more precise information on the topic. For sleep, REM and NREM were considered. In motor learning, motor adaptation task and motor sequence learning were searched. All duplicates were removed. Additionally, bibliographies of relevant articles were also examined. Only published full-text articles and papers in the English language were considered. The exclusion of non-English manuscripts is a limitation of this overview, since useful information might have been lost; however, inappropriate language interpretation could have led to inclusion of irrelevant information.

In total 131 articles were screened, while only 51 were considered relevant for this literature overview. Manuscripts were included in this overview if they fulfilled the following selection criteria: 1) studies or literature reviews published in English and in peer review journals, 2) articles had to be published between
1995 and 2019 and 3) articles clearly referred to the creation of motor memory, not to fact knowledge or other kinds of memory.

\section{Results}

The current literature on the consolidation of motor memory is described following specific proceedings that are distinguishable in a neurological way.

\section{Synaptic consolidation and sleep}

It is currently assumed that LTP is initiated in the awake phase and continued during SWS. Increased extracellular glutamate concentrations have been observed, which dropped after SWS. The same has been reported for the expression of the Cre and Arc genes and the protein $\mathrm{BDNF}[9,10]$. If the receptors NMDA or AMPA were blocked by drugs during sleep, consolidation did not occur. Those subjects even lost the learning effects of the training of the previous day [13, 35]. Furthermore, sleep spindles, an EEG pattern observed both in SWS and in the second stage, seem to indicate synaptic plasticity and are thought to reflect the reactivation of new encodings $[13,22,35]$. Specifically, the cortex is excited by the thalamus during the occurrence of sleep spindles in the SWS in a way that is more synchronous in time and space than is the case in the awake state. This leads to a fast and strong calcium influx after activation of the NMDA receptors, which triggers the LTP in both the thalamus and the cortex. Especially sleep spindles that occur during the transitions between sleep phases indicate changes in the enzyme cascades and in gene expression $[29,51]$. This coincides with the observation that OLI of different motor tasks correlates with an increase in sleep spindles or more generally, with a proportional increase in the second sleep stage [29]; however, a causal relationship has not yet been clarified [35]. This contrasts with the results of a study that prevented OLI the next day by a gamma-aminobutyric acid (GABA) inhibitor during sleep. The EEG patterns during the night showed significantly more sleep spindles compared to 
Manuelle Medizin 2021 · 59:26-32 https://doi.org/10.1007/s00337-020-00674-6

(c) The Author(s) 2020

L. Maltry · D. Ohlendorf · M. Bendels · D. A. Groneberg · C. Mickel

Does sleep contribute to the consolidation of motor memory? A literature review

Abstract

Background. It has been assumed that sleep promotes consolidation in motor learning; however, some publications have questioned its supposed effect. Differentiated statements on the subject are difficult because the conglomerate of influencing factors is large. The fact that memory, sleep, consolidation and motor task can be considered generic terms for different processes also contributes to the complexity.

Objective. The aim of this literature overview is to clarify the terminology and to describe what is known about how sleep contributes to the consolidation of motor memory regarding the different characteristics of consolidation and motor tasks.
Methods. A first literature screening in PubMed included the terms consolidation, sleep, memory, motor learning and memory in various combinations. Furthermore, keywords describing distinct parts of the generic terms were used for searching.

Results. The current evidence for the dependency of the different neurophysiological characteristics of the generic terms on sleep is presented including resulting contradictions and methodological criticism. Based on the literature, the question whether sleep promotes consolidation can only be answered in reductionist approaches and for individual influencing factors. The results even suggest that improvements in exercise quality may have been achieved through errors in study design, which, however, may lead to recommendations for future studies.

Conclusion. No final statement can be made on the subject at this time; however, at least it can be considered as evidence-based that sleep does not harm motor memory consolidation.

\section{Keywords}

Rapid eye movement - Slow wave sleep . Electroencephalography · Motor task · Motor learning

\section{Trägt der Schlaf zu Konsolidierung des motorischen Gedächtnisses bei? Ein Literaturreview}

\section{Zusammenfassung}

Hintergrund. Es wurde angenommen, dass Schlaf die Konsolidierung des motorischen Lernens fördert. Einige Publikationen haben jedoch seine angebliche Wirkung in Frage gestellt. Differenzierte Aussagen zum Thema sind schwierig, da das Konglomerat der Einflussfaktoren groß ist. Auch die Tatsache, dass Gedächtnis, Schlaf, Konsolidierung und die motorische Funktion als Oberbegriffe für verschiedene Prozesse gelten können, trägt zur Komplexität bei.

Ziel. Ziel dieses Literaturüberblicks ist es, die Terminologie zu klären. Des Weiteren soll beschrieben werden, was über den Beitrag des Schlafs zur Konsolidierung des motorischen Gedächtnisses hinsichtlich der unterschiedlichen Charakteristika von
Konsolidierung und motorischer Funktion bekannt ist.

Methoden. Eine erste Literaturrecherche in PubMed umfasste die Begriffe Konsolidierung, Schlaf, Gedächtnis, motorisches Lernen und Gedächtnis in verschiedenen Kombinationen. Darüber hinaus wurde mithilfe von Schlüsselwörtern gesucht, die verschiedene Teile der Oberbegriffe beschreiben.

Ergebnisse. Es werden die aktuellen Belege für die Abhängigkeit der verschiedenen neurophysiologischen Eigenschaften der Oberbegriffe des Schlafs einschließlich der daraus resultierenden Widersprüche und der methodischen Kritik vorgestellt. Die Frage, ob der Schlaf die Konsolidierung fördert, kann aufgrund der Literatur nur in reduktionistischen Ansätzen und für einzelne
Einflussfaktoren beantwortet werden. Die Ergebnisse legen sogar nahe, dass Verbesserungen der Übungsqualität durch Fehler im Studiendesign erreicht worden sein könnten, was jedoch zu Empfehlungen für zukünftige Studien führen kann. Schlussfolgerung. Eine abschließende Aussage zu diesem Thema kann zum jetzigen Zeitpunkt noch nicht gemacht werden. Es kann jedoch zumindest als evidenzbasiert angesehen werden, dass Schlaf die motorische Gedächtniskonsolidierung nicht beeinträchtigt.

\section{Schlüsselwörter}

Rapid eye movement · Langsamwelliger Schlaf · Elektroenzephalographie · Motorische Funktion - Motorisches Lernen the control group. A direct connection between sleep spindles and motor memory is therefore questionable; however, it remains unclear whether pharmacologically induced sleep spindles resemble normal sleep spindles [31].

Plasticizing effects could also be observed with theta waves in REM sleep, which seems to contribute mainly to the consolidation of memories with high emotional significance; however, it is assumed that REM mainly contributes to consolidation through its interaction with NREM [22, 35]. Regardless of the EEG patterns, imaging techniques were used to show that REM is involved in the consolidation of motor memory. If a receptor blocking substance was injected into the striatum during REM, OLI did not occur in motor tasks but was not prevented in declarative exercises [36]. During REM cholinergic activity is increased, which seems to play an important role in synaptic consolidation [13]. More detailed information on the development of the motor cortex in mice has been contributed by $\mathrm{Li}$ et al. [28], showing that dendritic spines of layer five pyramidal neurons can be pruned as well as strengthened in REM. It seems that REM has a multifaceted function in selectively remodelling new plasticity.

\section{Systemic consolidation and sleep}

An influential theory is the synaptic homeostasis hypothesis [46]. Here, slow wave activity $(<1 \mathrm{~Hz})$ is responsible for the downgrading of synaptic activity 
(synaptic downscaling). Thus, only weakly encoded compounds are deleted to create energy and space for the more significant ones [46, 47, 51]. Another argument in favor of such depotentiation is that less acetylcholine, serotonin and norepinephrine are released during SWS $[22,49]$. Due to the resulting disinhibition and synchronized activity in SWS, information from the hippocampus is transmitted into the neocortex $[22,35]$. According to this hypothesis, the promoting effect of sleep is more a by-product of synaptic downscaling $[13,51]$.

The synaptic homeostasis hypothesis might also play a role in motor memory. Training gripping task in rats led to increased transcription of the $c$-Fos and Arc genes in the relevant motor cortex. Both are known to be activity-dependently transcribed and involved in the formation of motor memory. During the subsequent sleep phase, an increase in slow wave activity was also documented only in the relevant motor cortex, which could not be found in other brain regions. This effect correlated with the learning performance previously achieved and lasted only $1 \mathrm{~h}$. In the same period of time, the c-Fos and Arc expression levels also returned to the original levels [19]. At the same time, contrary approaches are also being pursued, which assume an active reactivation of memory traces [2]. For example, it has been shown that protein synthesis is enhanced, especially during the SWS phases, and thus supports LTP [35]. Therefore, weak traces of memory could still be consolidated so that they are not forgotten during the subsequent further reduced brain activity phases. This seems to occur during the first 15-30 min of sleep, during a period of SWS; however, these reactivations are very unstable and also occur when awake, where they also influence memory performances [6].

According to another flow, the interaction of REM and NREM is important. The sequential hypothesis is currently increasingly coming into focus [41]. According to this theory, during SWS, systemic consolidation takes place in the sense of active reactivation, which triggers synaptic consolidation in the new brain areas in the subsequent REM. This may be in line with the synaptic homeostasis hypothesis [13].

\section{Offline improvements and motor tasks}

For both types of motor tasks, there is evidence that sleep promotes consolidation and MSL seems to depend particularly on the second stage of the NREM [41]. In MA, on the other hand, greater importance is attributed to SWS but this division is not final. According to Stickgold [44], the differentiated attribution of individual sleep phases to MA and MSL is probably not appropriate: "Instead, each stage of sleep seems to contribute differently to these processes, and we have proposed that the multiplicity of sleep stages has evolved, in part, to provide optimal brain states for a range of distinct memory consolidation processes" [44, p. 1273]. This is in line with the sequential hypothesis.

It has been proposed that sleep promotes consolidation especially if what has been learned has to be considered as relevant for future plans $[13,29]$. If test persons expect a reward for good learning success in an MSL task, much higher OLI occur for this sequence than for the less relevant one. This effect occurred regardless of the task order during training [18]. It has also been described that OLI is dependent on sleep when the subjects are aware of the repetitive character of the sequence of a fingertip task (explicit). Improvements of up to $20 \%$ have been reported [38]. If the test persons do not know that the sequence is repeated (implicit task definition), there are no differences in the offline effects with and without sleep. Therefore, it has been assumed that only the time span not the state of the brain is crucial for these kinds of tasks [11, 38]. Another study, however, has also shown that sleep promotes OLI also in implicit tasks [30]. Following the MSL task, brain activity during sleep was recorded via PET. The striatum and motor cortices were more active during REM than in a control group that had practiced a random sequence. In the re-test on the following day, OLIs were measurable. Furthermore, there are indications of distinct roles of the individual sleep phases. For example, the number of sleep spindles in the second sleep stage after a fingertip task increases significantly [32]. In addition, OLI can correlate with the amount of sleep stage two in the last quarter of the night [50]. A detailed analysis of a fingertip task on a dial revealed that some transitions between keys were easier and faster than others. After a sleep phase it became apparent that these problematic transitions in particular had improved [27]. This unification could lead to a better performance automation and hence in speed across the motor program [50]. This suggests that the importance of sleep in consolidation goes beyond the mere reactivation of fresh encodings. There seems to be a selection process that facilitates the retrieval of motor memory.

Research has also focused on MA tasks. Classically, rotatorically deflected cursors have been used. After a few attempts the movement can be carried out almost without errors. The task is implicit, without instructions for perturbation, the subject is only asked to point with the cursor to targets. Subsequent EEG during sleep may locally show an increase in slow oscillations associated with SWS during the first $30 \mathrm{~min}$ of NREM. Additionally, OLI also appear. Both were not detectable in the control group [21].

\section{Stabilization and motor tasks}

It is controversial whether stabilization occurs in all tasks and if sleep is necessary at all $[14,49]$. The research literature is less extensive than for MSL. In a study on gross motor learning of a MA task (riding an inverse bike), Bothe et al. [3] have shown that a training set-up of eveningmorning-evening (PM-AM-PM) is superior compared to AM-PM-AM in speed and accuracy. The authors related the stabilization to sleep spindles in the right hemisphere. Korman et al. [25] examined whether a second exercise would prevent the OLI in the re-test. The authors were able to show that sleep could shorten the time course of consolidation, both for OLS and for OLI. Accordingly, the neurophysiological processes do not 


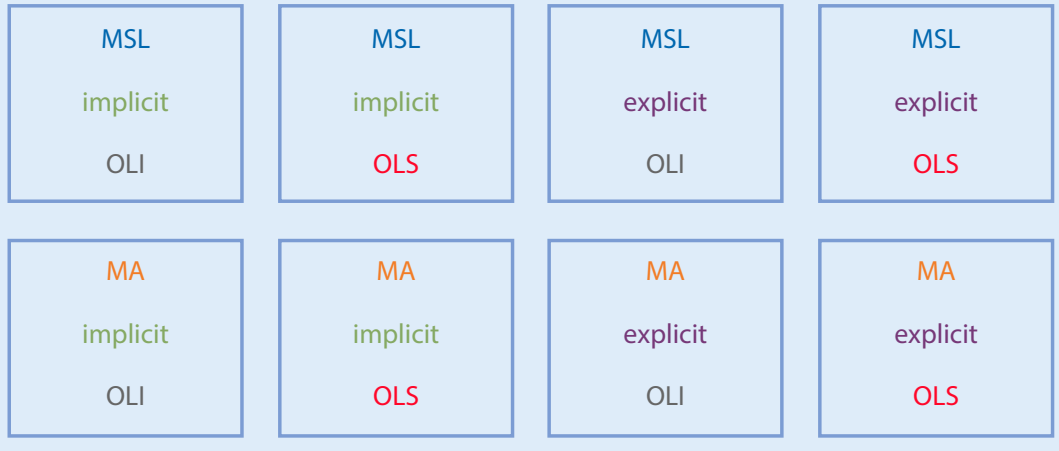

Fig. $1 \Delta$ Possible combinations of tasks for motor learning. These influencing factors cause differences in the neuronal processing of memory traces. MSL motor skill learning, MA motor adaptation, OLI offline improvements, $O L S$ offline stabilization

appear to be separate but interacting. On this basis, it is further assumed that both sleep and an awake offline phase lead to consolidation but the underlying mechanisms are different. During the awake phase, synaptic consolidation may be responsible for OLS by strengthening encoding through synaptic plasticity. During sleep, OLS are caused by systemic consolidation. Here, the memory track is integrated into the long-term memory. In addition, invariants that do not improve the quality of movement could be removed [14].

\section{Discussion}

Research into consolidation in motor memory depends on a variety of factors, especially with respect to the importance of sleep. The manifold combination possibilities seem to be the main reason why the study situation is unclear or contradictory. First, many studies focused on hippocampus-dependent learning. This usually refers to a form of declarative memory; however, as the presented studies with imaging methods have shown, this structure is also involved in the formation of motor memory, at least in healthy subjects. This applies regardless of whether the task is implicit or explicit. It is therefore questionable whether the distinction between declarative (explicit) and motor (implicit) memory according to the classical paradigm in the consolidation studies and also the sleep dependency makes sense. Another problem is that the term consolidation is used as a generic term for various processes and observations. Which neurophysiological conditions correlate with OLI and OLS have not been clarified; however, it can be assumed that these are not independent processes. Both result from changes in spatial, temporal or motor components of movement. If only the overall stabilization or the overall improvement is measured, some of these components may be masked. Moreover, the differentiation between MA and MSL also contributes to the complexity of the topic. Both are based on different neurophysiological processes and especially the striatum and cerebellum contribute to the learning process in different ways; however, the tasks which depend on these structures during sleep are only rudimentarily known. Nevertheless, evidence for improved consolidation during sleep could be found for both MSL and MA.

The distinction between explicit and implicit tasks also seems to have an influence on the importance of sleep. It is widely assumed that sleep-dependent consolidation processes occur only through explicit statements and with the implicit option the time elapsed is sufficient; however, other studies suggest that sleep could play a role in both options.

In total, these factors potentially influencing the neurophysiological consolidation pattern taken into account in this article, lead to eight possible combinations for different neurophysiological consolidation processes (- Fig. 1). It is possible that the neurophysiological processes af- ter training will be different in each of these combinations and will also lead to slightly different levels of motor knowledge.

A systematic analysis of existing studies from these points of view could contribute to further clarification, but this presentation does not yet take into account the fact that consolidation takes place on a synaptic and systemic level. To what extent this correlates with which phenomenological performance development remains unclear. The same applies to the question of whether consolidation processes run more efficiently during sleep. Although reductionist approaches attempt to link individual sleep phases or EEG patterns with these forms of consolidation, the results to date point in no clear direction. In total, however, the evidence described suggests that sleep has a positive effect on the consolidation of motor memory [24]. Yet, there are also publications in which this is doubted [5, 33, 37]. In a meta-analysis, Pan and Rickard [33] criticized the study design and data evaluation in studies on explicit MSL. This includes determining the average for the calculation of prepost improvements. Usually the performance at the end of the training and at the beginning of the re-test is averaged over a certain number of tests. The larger the amount of data included, the more precise the estimation of the respondent's performance becomes; however, one disadvantage is that the learning effect that occurs during this period (online improvements) distorts the data. "At one extreme, averaging over online learning could account for all of the postdelay gain" [33, p. 814]. Furthermore, the level at which the subject is at the end of training is decisive. While the learning curve is still relatively steep at the beginning of the training, it flattens out after a few repetitions and finally results in a plateau. If the training session is finished without a plateau, the average calculation of the data has an even more drastic effect. In addition, OLI may also have revealed through an accumulation of reactive inhibition during training. Usually a cycle of $30 \mathrm{~s}$ exercise-30s break is used in MSL studies. Reactive inhibition reduces performance during 
the exercise phase. Towards the end of the training this can be observed due to fatigue. In the re-test after a long break (asleep or awake), the drop in performance during the exercise is less. As a result, the average performance at the end of the workout appears worse than at the beginning of the re-test [5, 33].

All three factors have a decisive influence on the study results, which is why the evidence on OLI and MSL must be viewed critically. Only the study by Rickard et al. [37] took these parameters into account and found no sleepdependent OLI. Nevertheless, it would be possible to consolidate more effectively during sleep and produce more stable traces of memory. This means that consolidation does not necessarily have to be measurable as OLI.

In future studies, the suggestions of Pan and Rickard [33] should be followed in order to avoid the abovementioned bias at least for MSL studies. Instead of averaging the data from training and retest, the courses of the learning curves could be examined (continuity analyses). The three parameter power function can be placed over the learning curves in such a way that no difference is expected between training and post-test. Should OLI occur, these would be noticeable. In addition, care should be taken to ensure that a plateau has already formed when the training is aborted. To minimize the influence of reactive inhibition, the exercise blocks should be shortened to $10 \mathrm{~s}$ (still with $30 \mathrm{~s}$ break). With such an experimental set-up, however, Rickard et al. [37] were not able to detect any sleepdependent OLI. In addition, the study designs must take into account the observations that the complexity of the task, the motivation of the test persons, the intensity of the task [45] and the temporal organization of the measurements also seem to have an influence on the sleep dependency of the consolidation. Meaningful conclusions can only be drawn once methodologically sound work has been carried out on the possible combinations of the influencing factors described. So far, it is certain that sleep does no harm to consolidation in the motor memory.

\section{Conclusion}

- There are a number of studies that show that sleep promotes the consolidation of motor memory.

- In other articles the importance of sleep for consolidation is questioned. The authors relied largely on methodological criticism of the studies that have shown sleep-dependent consolidation.

- Concrete statements on a neurophysiological level are difficult to make because the generic terms consolidation, sleep, memory and motor task each combine different specifications which are based on different neurophysiological processes.

- On the basis of the available studies, no recommendations can be made for training practice; however, it is certain that sleep does not harm the consolidation of motor memory.

\section{Corresponding address}

\section{Laura Maltry}

Institut für Arbeitsmedizin, Sozialmedizin und Umweltmedizin, Goethe-Universität

Theodor-Stern-Kai 7, Haus 9b, 60590 Frankfurt am Main, Germany

Maltry@med.uni-frankfurt.de

Funding. Open Access funding provided by Projekt DEAL.

\section{Compliance with ethical guidelines}

Conflict of interest. L. Maltry, D. Ohlendorf, M. Bendels, D.A. Groneberg and C. Mickel declare that they have no competing interests.

Ethical standards. For this article no studies with human participants or animals were performed by any of the authors. All studies performed were in accordance with the ethical standards indicated in each case.

Open Access. This article is licensed under a Creative Commons Attribution 4.0 International License, which permits use, sharing, adaptation, distribution and reproduction in any medium or format, as long as you give appropriate credit to the original author(s) and the source, provide a link to the Creative Commons licence, and indicate if changes were made. The images or other third party material in this article are included in the article's Creative Commons licence, unless indicated otherwise in a credit line to the material. If material is not included in the article's Creative Com- mons licence and your intended use is not permitted by statutory regulation or exceeds the permitted use, you will need to obtain permission directly from the copyright holder. To view a copy of this licence, visit http://creativecommons.org/licenses/by/4.0/.

\section{References}

1. Andrés I de, Garzón M, Reinoso-Suárez F (2011) Functional anatomy of non-REM sleep. Front Neur 2:70

2. Born J, Feld GB (2012) Sleep to upscale, sleep to downscale: balancing homeostasis and plasticity. Neuron 75:933-935

3. Bothe K, Hirschauer F, Wiesinger HP et al (2019) Gross motor adaptation benefits from sleep after training. J Sleep Res. https://doi.org/10.1111/jsr. 12961

4. Brashers-Krug T, Shadmehr R, Bizzi E (1996) Consolidation in human motor memory. Nature 382:252-255

5. Cai DJ, Rickard TC (2009) Reconsidering the role of sleep for motor memory. Behav Neurosci 123:1153-1157

6. Carr MF, Jadhav SP, Frank LM (2011) Hippocampal replay in the awake state: a potential substrate for memory consolidation and retrieval. Nat Neurosc 14:147-153

7. Cellini N (2017) Memory consolidation in sleep disorders. Sleep Med Rev 35:101-112

8. Christova M, Aftenberger $\mathrm{H}$, Nardone Ret al (2018) Adult gross motor learning and sleep: is there a mutual benefit? Neural Plast 2018:3076986

9. Cirelli C, Gutierrez CM, Tononi G (2004) Extensive and divergent effects of sleep and wakefulness on brain gene expression. Neuron 41:35-43

10. Cirelli C, Tononi G (2000) Differential expression of plasticity-related genes in waking and sleep and their regulation by the noradrenergic system. JNeurosci 20:9187-9194

11. Dayan E, Cohen LG (2011) Neuroplasticity subserving motor skill learning. Neuron 72:443-454

12. Delrosso LM, Hoque R (2014) The cerebellum and sleep. Neurol Clin 32:893-900

13. Diekelmann S, Born J (2010) The memory function of sleep. Nat Rev Neurosci 11:114-126

14. Diekelmann S, Born J (2007) One memory, two ways to consolidate? Nat Neurosci 10:1085-1086

15. Doyon J, Benali H (2005) Reorganization and plasticity in the adult brain during learning of motor skills. Curr Opin Neurobiol 15:161-167

16. DudaiY (2004)Theneurobiology of consolidations, or, how stable is the engram? Annu Rev Psychol 55:51-86

17. Dudai Y, Karni A, Born J (2015) The consolidation and transformation of memory. Neuron 88:20-32

18. Fischer S, Born J (2009) Anticipated reward enhances offline learning during sleep. J Exp Psychol Learn Mem Cogn 35:1586-1593

19. Hanlon EC, Faraguna U, Vyazovskiy VV et al (2009) Effects of skilled training on sleep slow wave activity and cortical gene expression in the rat. Sleep 32:719-729

20. Hikosaka O, Nakamura K, Sakai K et al (2002) Central mechanisms of motor skill learning. Curr Opin Neurobiol 12:217-222

21. Huber R, Ghilardi MF, Massimini Met al (2004) Local sleep and learning. Nature 430:78-81

22. Hutchison IC, Rathore S (2015) The role of REM sleep theta activity in emotional memory. Front Psychol 6:1439

23. Karni A, Meyer G, Rey-Hipolito C et al (1998) The acquisition of skilled motor performance: fast and 
slow experience-driven changes in primary motor cortex. Proc Natl Acad Sci USA 95:861-868

24. King BR, Hoedlmoser $K$, Hirschauer $F$ et al (2017) Sleeping on the motor engram: the multifaceted nature of sleep-related motor memory consolidation. Neurosci Biobehav Rev 80:1-22

25. Korman M, Doyon J, Doljansky J et al (2007) Daytime sleep condenses the time course of motor memory consolidation. Nat Neurosci 10:1206-1213

26. Krakauer JW, Shadmehr R (2006) Consolidation of motor memory. Trends Neurosci 29:58-64

27. Kuriyama K, Stickgold R, Walker MP (2004) Sleepdependent learning and motor-skill complexity. Learn Mem 11:705-713

28. Li W, Ma L, Yang $G$ et al (2017) REM sleep selectively prunes and maintains new synapses in development and learning. Nat Neurosci 20:427-437

29. Lindemann C, Ahlbeck J, Bitzenhofer SH et al (2016) Spindle activity orchestrates plasticity during development and sleep. Neural Plast 2016:5787423

30. Maquet P, Laureys S, Peigneux P et al (2000) Experience-dependent changes in cerebral activation during human REM sleep. Nat Neurosci 3:831-836

31. Morgan PT, Kehne JH, Sprenger KJ et al (2010) Retrograde effects of triazolam and zolpidem on sleep-dependent motor learning in humans. JSleep Res 19:157-164

32. Morin A, Doyon J, Dostie V et al (2008) Motor sequence learning increases sleep spindles and fast frequencies in post-training sleep. Sleep 31:1149-1156

33. Pan SC, Rickard TC (2015) Sleep and motor learning: is there room for consolidation? Psychol Bull 141:812-834

34. Podolski I (1998) Possibility of "superfast" consolidation of long-term memory. Membr Cell Biol 11:743-752

35. Rasch B, Born J (2013) About sleep's role in memory. Physiol Rev 93:681-766

36. Rasch B, Gais S, Born J (2009) Impaired off-line consolidation of motor memories after combined blockade of cholinergic receptors during REM sleep-rich sleep. Neuropsychopharmacology 34:1843-1853

37. Rickard TC, Cai DJ, Rieth CA et al (2008) Sleep does not enhance motor sequence learning. J Exp Psychol Learn Mem Cogn 34:834-842

38. Robertson EM, Pascual-Leone A, Miall RC (2004) Current concepts in procedural consolidation. Nat Rev Neurosci 5:576-582

39. Schendan HE, Searl MM, Melrose RJ et al (2003) An FMRI study of the role of the medial temporal lobe in implicit and explicit sequence learning. Neuron 37:1013-1025

40. Shadmehr R, Holcomb HH (1997) Neural correlates of motor memory consolidation. Science 277:821-825

41. Siengsukon CF, Boyd LA (2009) Does sleep promote motor learning? Implications for physical rehabilitation. Phys Ther 89:370-383

42. Squire LR (2009) The legacy of patient H.M. for neuroscience. Neuron 61:6-9

43. Stanley J, Krakauer JW (2013) Motor skill depends on knowledge of facts. Front Hum Neurosci 7:503

44. Stickgold R (2005) Sleep-dependent memory consolidation. Nature 437:1272-1278

45. Thomas R, Johnsen LK, Geertsen SS et al (2016) Acute exercise and motor memory consolidation: the role of exercise intensity. PLoSONE 11:e159589
46. Tononi G, Cirelli C (2003) Sleep and synaptic homeostasis: a hypothesis. Brain Res Bull 62:143-150

47. Tononi G, Cirelli C (2006) Sleep function and synaptic homeostasis. Sleep Med Rev 10:49-62

48. Ungerleider LG, Doyon J (2002) Functional anatomy of motor skill learning. In: Schacter DL, Squire LR (eds) Neuropsychology of memory. Guilford, New York

49. Walker MP (2005) A refined model of sleep and the time course of memory formation. Behav Brain Sci 28:51-64 (discussion 64-104)

50. Walker MP, Stickgold R (2006) Sleep, memory, and plasticity. Annu Rev Psychol 57:139-166

51. Wang G, Grone B, Colas D et al (2011) Synaptic plasticity in sleep: learning, homeostasis and disease. Trends Neurosci 34:452-463

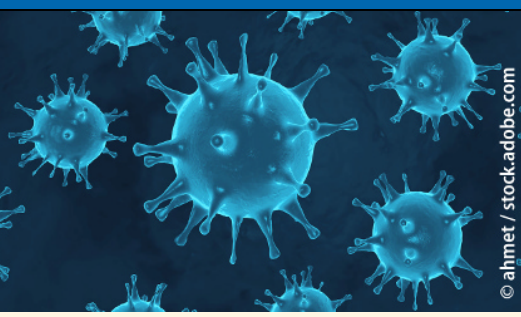

\section{Aktuelle Entwicklung zu \\ COVID-19 bei Springer Nature und Springer Medizin}

Springer Nature und Springer Medizin unterstützen die globale Reaktion auf die COVID-19-Pandemie, indem ein schneller und direkter $\mathrm{Zu}$ gang zu den neuesten verfügbaren Forschungsergebnissen und Daten ermöglicht wird.

Auf der Homepage SpringerMedizin.de finden Sie ein immer aktuelles Dossier mit Beiträgen, Forschungsarbeiten und Ergebnissen zu SARS-CoV-2 sowie relevanten Links.

Darin z.B. auch die kürzlich publizierte

Empfehlung von DIVI, DGIIN, DGAI und DGP zur Intensivtherapie von Patienten mit COVID-19.

Springer Nature arbeitet mit globalen Organisationen zusammen, und verlinkt über SpringerNature.com/de auf eine eigene Landingpage mit einer Vielzahl an Information sowie freiem Zugriff auf die COVID-19-Contentplattformen von Nature Research, BioMed Central (BMC) und Springer.

Das Dossier zu Coronavirus / Covid-19 von Springer Medizin finden Sie hier: www.springermedizin.de/covid-19

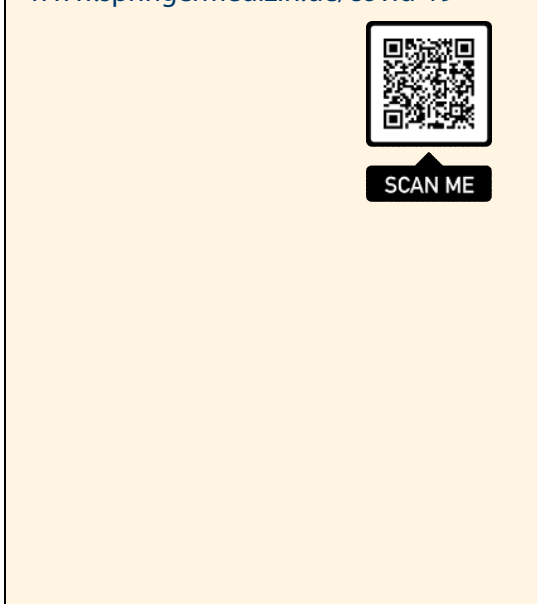

